\title{
Transcatheter Cardiovascular Therapeutics (TCT) conference 2018
}

\author{
Sudarshana Datta* \\ Department of Cardiology, Harvard Medical School, USA
}

Submission: October 04, 2018; Published: November 13, 2018

*Corresponding author: Sudarshana Datta,Postdoctoral Research Fellow, PERFUSE study group, Department of Cardiology, BIDMC, BaimInstitue for Clinical Research, Harvard Medical School, 930 Commonwealth Avenue, 02215, USA

Keywords: Cardiovascular; Transcatheter mitral; Medical therapy, Heart failure; Microvasculature

\section{Opinion}

The 30th annual Transcatheter Cardiovascular Therapeutics (TCT) conference 2018 held in sunny San Diego, California, was replete with surprises. The landmark COAPT trial was a clear home run, showcasing that transcatheter mitral valve approximation using the MitraClip, on a background of maximally tolerated guideline-directed medical therapy (GDMT) was superior to GDMT alone in the reduction of Heart Failure (HF) hospitalization and mortality in symptomatic heart failure patients with grade 3-4+ Mitral regurgitation (MR). Spectacularly, device-based treatment resulted in a significantly lower rate of hospitalization for heart failure, lower mortality, and better quality of life and functional capacity within 24 months of follow-up than medical therapy alone. As similar trials in Europe had been negative and the surgical literature for functional MR ran along the same lines, the low expectations made the contrasting results appear all the more staggering. Interventionalists attributed these findings to endpoints such as repeat hospitalization for heart failure and the meticulously selected population, stating effectiveness in the real world would hinge on how closely doctors could replicate the enrolled patient group. Indeed, 'MitraClip should be done for the right reasons in the right group of patients,' was the take-home message.

Delving deep into the coronary microvasculature, the CorMicA trial paved the way for new insights into mechanisms and disease-modifying therapy for angina patients with no obstructive coronary artery disease (CAD). Ford et al. demonstrated how adjunctive testing of coronary vascular function during coronary angiography followed by medical therapy targeted to the findings, improved angina outcomes. While the results were only applicable to severely symptomatic patients at baseline, there was no denying the fact that microvascular angina could be extremely disabling, underlining the importance of titration of therapies in afflicted patients.
PREPARE-CALC was based on the concept that heavily calcified de novo coronary lesions were difficult and needed to be prepared using balloon modification techniques (MB) or upfront high-speed rotational atherectomy (RA) in order to allow successful stent implantation. Dr. Gert Richardt reported excellent success rates with strategy success being significantly more common in the RA vs MB group (98\% versus $81 \%$ ). Moreover, patients had a crossover to RA in case MB failed, with an extraordinarily high success rate in this group. Dr.Richardt spoke about the possibility of bailout or 'Rota-regret' stating, "Depending on your experience and preference, you can do the heavily calcified lesions either with upfront rotablation electively or you can start with a balloon. But if you start with the latter, you have to be prepared for a crossover or a bailout situation. Either way, you have to be trained in the technique of rotational atherectomy." While the results of the trial were expected, it was a good question to raise, keeping in mind the shorter duration and cost-effectiveness of MB, in comparison with RA.

In the long saga of ABSORB trials, the encouraging results of ABSORB IV showed that polymeric coronary bioresorbable vascular scaffolds (BVS) were non-inferior to cobalt-chromiumbased Xience DES for cardiovascular outcomes of target lesion failure and angina in fairly simple lesion types, in a 1 year period. Although the results were better for BVS compared with ABSORB III, there was also an improvement in the results in the Xience DES arm. Comparing the study to ABSORB III, the primary investigator, Dr. Stone commented, "It was a very, very interesting study. Better technique, better patient selection, and appropriate types of lesions do bring down this difference and I honestly believe that now all we need is a better device that will hopefully eliminate most or all of these early first 3 year differences, potentially allowing the long-term benefits of ABSORB to emerge." 
ULTIMATE established the superiority of IVUS-guided PCI over angiography-guided PCI in the prevention of target vessel failure in an all-comers population. The findings did not seem to come as a surprise to most interventionalists. 'IVUS provides extremely useful information about edge dissection, the exact size after one post-dilates, the status of the plaque burden and helps ensure there is good stent apposition. While it is a good idea to perform IVUS routinely, cost issues and the extra time taken may serve as drawbacks,' Dr. Deepak Bhatt, Executive Director of Interventional Cardiovascular Programs, Brigham and Women's Hospital, remarked.

Results of the SOLVE-TAVI trial comparing self-expanding CorevalveEvolut $\mathrm{R}$ and balloon-expandable Edwards Sapien 3 valves revealed equivalence in Transcatheter Aortic Valve Implantation (TAVI) in a head-to-head comparison in terms of decreasing all-cause mortality, moderate or severe prosthetic valve regurgitation, and permanent pacemaker implantation. The burr under the saddle was that more patients assigned the balloon-expandable valve had a stroke vs. those assigned the self-expanding valve $(4.7 \%$ vs. $0.5 \%)$. While some attributed post-dilatation in balloon expandable valves or a play by chance to these findings, it was agreed that a well powered, investigatorinitiated trial could nail this question.

Of the raging stent wars, ReCr8 established noninferiority of Polymer-free amphilimus-eluting stents (PF-AES) in comparison with permanent-polymer zotarolimus-eluting stents (PP-ZES) in terms of target-lesion failure at 12 months. SORT-OUT, too confirmed noninferiority of polymer free Biolimus A9-coated BioFreedom stent as compared to the thin strut, biodegradable polymer cobalt-chromium sirolimus-eluting Orsiro stent in an all-comers patient population, at 12 months. BIONYX, conducted by Clemens von Birgelen et al. in an all-comers population, reported non-inferiority of the novel Resolute Onyx stent versus the Orsiro stent for the primary endpoint of safety and efficacy at 1-year. Finally, IMPERIAL comparing the Eluvia paclitaxeleluting stent (Boston Scientific) to Zilver PTX paclitaxel-eluting stent (Cook Medical) showed that the Eluvia stent outperformed Zilver in terms of efficacy, which was defined as primary patency at 12 months. Pondering the implications of all these battles, Dr. Roxana Mehran, Director of Interventional Cardiovascular Research and Clinical Trial, Mount Sinai School of Medicine, commented, "I don't know what it all means. I think it probably just means that the competitive world is going to be big on which drug-eluting stent you choose and it's going to really become all about pricing. Don't you think that's a good thing? If there's a lot of competition, the driver of the prices will go down."Barring the gripping presentations, debates, and discussions of all the latebreaking trials of TCT 2018, the interactive training workshops too provided clinicians an exceptional and fun-filled learning experience.

\section{Your next submission with Juniper Publishers} will reach you the below assets

- Quality Editorial service

- Swift Peer Review

- Reprints availability

- E-prints Service

- Manuscript Podcast for convenient understanding

- Global attainment for your research

- Manuscript accessibility in different formats

( Pdf, E-pub, Full Text, Audio)

- Unceasing customer service

Track the below URL for one-step submission https://juniperpublishers.com/online-submission.php 